\title{
Stories about care: Women in a historically disadvantaged community infected and/or affected by HIVIAIDS
}

\author{
Julian C Müller \& Sunette Pienaar ${ }^{1}$ \\ Department of Practical Theology \\ University of Pretoria
}

\begin{abstract}
Black women in previously disadvantaged communities in South Africa carry the burden of triple oppression: (a) the social engineering policies synonymous with apartheid have marginalised women economically and socially; (b) patriarchy, embedded in cultural and religious discourses, has rendered women voiceless and powerless and (c) HIVIAIDS targets the most vulnerable: women and children. The authors describe a research experience in Atteridgeville, a historically disadvantaged community in South Africa, with a family of women infected and/or affected by HIVIAIDS, about their experiences of care and or the lack thereof. A narrative approach offers useful ideas to facilitate a process in which African women in historically challenged communities can speak out about their experiences of care and or the lack of care.
\end{abstract}

\section{BACKGROUND TO THE RESEARCH EXPERIENCE}

\subsection{An incomprehensible calamity}

The current government's policies have begun to have effect since its election during the first democratic elections in 1994 and during the past three years South Africa has experienced reasonable growth. Yet fate has dealt the country a cruel blow, replacing apartheid with HIV as public enemy number one (Whiteside \& Sunter 2000:118). The HIV pandemic has entered our consciousness as an incomprehensible calamity. HIVIAIDS has claimed millions of lives, inflicting pain and grief, causing fear and uncertainty, and threatening the economy.

\footnotetext{
${ }^{1}$ Julian Müller is professor in Practical Theology at the University of Pretoria and Dr Sunette Pienaar graduated recently under his supervision. They worked together on this article, but she was the researcher who did the fieldwork. Through this article we pay tribute to Prof Andries Breytenbach for his friendship and the high standards of research that were set by him.
} 


\subsection{The triple oppression of black women}

Black women in historically challenged communities in South Africa carry the burden of triple oppression: (a) the social engineering policies synonymous with apartheid have marginalised women economically and socially; (b) patriarchy, embedded in cultural, traditional, gender and religious discourses, has rendered women voiceless and powerless and (c) HIVIAIDS is targeting the most vulnerable: women and children. Not only are women carrying the brunt of HIV infections, but they also carry the extra burden of caring for the sick and the dying.

For at least a decade we have known that gender and sexuality (and patriarchy) are significant factors in the sexual transmission of HIV, and we now know that they also influence treatment, care and support. Imbalance in power between women and men restricts women's sexual autonomy and expands men's sexual freedom. Women's access to treatment and care also proves more limited than that of men since women spend their available resources on children and the household before attending to their own health needs. Women are also often solely responsible for raising children, since their partners are absent or deny responsibility.

Across cultures a consistent finding is the fact that there are differences between women's and men's roles, their access to productive resources and to decision-making authority. Men are seen as responsible for productive activities outside the home and women for reproductive and productive activities within the home, which explains women's roles as, predominantly, caregivers (Jobson 2000:3). Women almost exclusively bear the brunt of providing care and support for the chronically sick and the orphans at home, at hospital and in home care programmes. The government relies on this socially constructed role of women as caregivers to promote and implement a strategy of home and community based care. This amounts to downloading the costs of care onto the women in the communities.

\subsection{Research aims and objectives}

The main aim of this research was to reach a holistic understanding of the untold stories of women in historically challenged communities, infected and affected by HIVIAIDS, and specifically about their experiences of care and the lack of care.

In order to achieve this aim, I drafted more specific objectives. The first objective was to deconstruct discourses embedded in patriarchy, gender, and culture in order to empower women infected/affected by HIVIAIDS to tell their stories about care and/or the lack of care. I endeavoured to use post-modern narrative social construction discourse (Freedman \& Combs 1996:22) and 
post-modern theologies. The second objective was as a narrative researcher, to be part of the "story development" process through which different alternative, more holistic stories of care could be explored.

\section{RESEARCH PARADIGM AND METHODOLOGY}

\subsection{A post-modern epistemology}

Black women in historically disadvantaged communities in South Africa have suffered unimaginable pain, humiliation and discrimination at the hands of social engineering and patriarchal and cultural discourses. I wanted to ensure that I did not in any way victimise the family of women in my research experience which would have compounded their burdens. I position myself within a post-modern paradigm. We argue a narrative approach, as an ethical, accountable approach to undertaking research with oppressed black South African women. ${ }^{2}$

\subsection{Theological stance}

Theology and practical theology play an important role in this research. Modern theologies have kept discourses on gender, culture and patriarchy alive in our communities. To a great extent the theology of the Dutch Reformed Church in South Africa still condones and reinforces discourses embedded in white, westernised theology.

Discourses embedded in gender, patriarchy and culture that render women infected/affected by HIVIAIDS powerless to make decisions about care, are challenged by post-modern theology, which is, in a sense, a rediscovery of the value of human participation and a quest for wholeness and meaning (Herholdt 1998a:218).

A post-modern approach to practical theology and thus pastoral therapy needs to be holistically integrated with the task of social transformation (Gerkin 1997:74). In pastoral therapy, the prophetic tradition offers an alternative perception of reality (Brueggemann 1987:110). In terms of my research, the most useful aspects of the prophetic tradition are its concern for justice, and its awareness of systemic evil and people's dominance of others. The prophetic tradition in pastoral therapy is, therefore, linked to the ethical considerations of post-modern theologies. A post-modern theology underpins my epistemology.

Feminist theologians strive to bring out an alternative story of Christianity, a story of liberation, justice, equality and dignity. Griffen (1989:8) states that post-modern theology is supportive of feminist or post-patriarchal

${ }^{2}$ The empirical research was done by Sunette Pienaar 
theology. Post-modern and post-structuralist feminism "view the world as endless stories or texts, many of which sustain the integration of power and oppression and actually constitute [women] as subjects in a determinant order" (Olesen 1994:164). My research therefore needed to acknowledge the stories told by the women whilst simultaneously deconstructing the power relationships inherent to these stories. Practical post-modernist theology which insists on doing right rather than being right, is in line with African Women's Theology where story telling is part of the doing.

African women's theology pleads to be deconstructed to allow for a definition of a white African feminist theology which "is not dependent on the philosophical meta-language of traditional theologies, but on the language of storytelling" (Landman 1998:138), and which includes the life stories of black women. I cannot speak on behalf of black women, as that would be presumptuous and unethical. I am however, ethically responsible to deconstruct the racial discourse of power and to create the opportunity for our black oppressed sisters to tell their stories in their own voices.

Modern discourse and positivist theology place pastoral therapists in a superior and therefore powerful position (Dill 1996). Theology reacted to and embraced a positivistic methodology, which has led to foundationalist theology. Foundationalist theology claims that a pastoral therapist is an expert on the Bible. In foundationalist theology the pastoral therapist and client are not free equals since the knowledge of the pastoral therapist becomes a source of power for the pastoral therapist's power, who therefore controls the relationship (Botha 1998:152).

A narrative approach to pastoral therapy may change the hierarchical relationship in therapy (Botha 1998:154). The client is seen as the expert of her or his life, ensuring that the therapist no longer is an untouchable expert (Anderson \& Goolishian 1992:29). Post-modern social construction discourse insists that people with "expert" knowledge are not the only ones to be listened to when decisions are made. A narrative approach in pastoral therapy is one of the possible approaches which could situate itself within postmodern social constructionist discourse as epistemology.

\subsection{Listening to the stories of women}

I am committed to research that will "not only contribute to the transformation of our society through care with the marginalised and disadvantaged, but also address cultural discourses and societal practices that promote injustices" (Kotzé \& Kotzé 1997:viii). 


\subsubsection{The social constructionist discourse}

The social construction discourse is situated within the post-modern discourse and holds that "the idea that objective knowledge is impossible; and therefore 'multiple realities are preferred" (Kotzé 1994:21). The post-modern view of knowledge is that "values infuse all knowing" and therefore "postmodernism typically values diversity, plurality, and choice" (Hare-Mustin 1997:569). Social construction discourse not only provides a lens (epistemology) through which to view the reality of my context and this research experience, but also empowered me to constitute realities in relationships and language.

This paradigm, then, takes a "critical stance towards taken-for-granted knowledge" and works from the vantage point that the "ways in which we commonly understand the world, the categories and concepts we use, are historically and culturally specific" (Burr 1995:3). The specific cultural context within which women infected and/or affected by HIVIAIDS are cared for and are taken care of and the taken-for-granted ideas that inform this reality would therefore need to be discussed in this construction.

Feminist research has been innovative in its choice to study particular groups of women formerly ignored by social science. Feminist researchers use both quantitative as well as qualitative research methods in this endeavour. I studied a black family of women infected and affected by HIVIAIDS in a previously disadvantaged community. I was involved with ethnography and participatory action research, making use of semi-structured and unstructured interviews in my research experience. These methods of research belong to the qualitative paradigm of research.

My research became "co-research" or, as Dixon (1999:45) prefers, "cosearch" in the real sense of the word, since my beliefs, my preconceived ideas and my personal feelings were challenged. I realised that "hiding the 'I"' is pretence, a fraud that forces me to hide my passion, to deny who I am, and to pretend that my words are separate from me. Acknowledging the "l" allows me to reveal myself and my feelings (Dudley-Marling 1996:36). Typically, personal experience is irrelevant in mainstream research, or is thought to contaminate a project's objectivity. In feminist research, by contrast, it is relevant and repairs the project's pseudo-objectivity.

\subsection{2 "In Africa we do things together through stories"}

Narrative research is situated within the broader domain of qualitative social science research. The narrative study of lives is a growing, multidisciplinary tradition of research. The narrative world view proposes that human beings are interpreting beings and that we are active in interpreting our experiences 
as we live our lives (White 1995b:13). I therefore aimed to listen to the many stories that constitute the world of South African women, HIVIAIDS and care.

These women live their lives according to the stories that they have about their lives, stories that actually shape their lives, constitute their lives and "embrace" their lives (White 1995b:14). Freedman and Combs (1996:31) suggest that when therapists (in this case "researchers") listen to people's stories in order to "make an assessment," to "take a history of the illness" or "offer an interpretation," they are approaching people's stories from a modernist, "structuralist" point of view. However, within a post-modern social constructionist world view, it is important to attend to cultural and contextual stories as well as to individual people's stories.

Narrative researchers such as Müller et al (2001:76-96) argue that the crisis also includes the use and abuse of research and the need to deconstruct the sometimes abusive power relations which saturate research projects. In an effort to deconstruct the power relations narrative researchers choose not to use language such as "research objects" or "research population", but rather refer to them as research participants or coresearchers. This cooperation then means that the purpose of the research is not to reach the objectives of the researcher, but should also be meaningful to the persons or groups that form the basis of the research. Research, in this instance, is not about change, but about listening to stories and about becoming "part" of the stories. The researcher strives towards participating inter-action. Through participation, action is possible which is neither abusive nor victimising.

Viewing the research question from a narrative angle entails stories/events which, in the course of time, are linked together to form a plot (Morgan 2000:5). Patriarchal, gender, and cultural discourses all form part of the stories told. But these discourses have rendered power to men in our society, while women and children have been subjugated by this power. By deconstructing these discourses, space can be opened up for alternative understandings or insights, and the speaking out of those who are marginalised by the discourse.

A narrative approach thus offers useful ideas to facilitate a process in which African women in historically challenged communities, infected and/or affected by HIVIAIDS, can speak out about their experiences of care and or the lack of care.

\subsection{Methodological process}

The methodological process used in this research project is based on the article of Müller et al (2001:76-96). These authors used Anne Lamott's model 
for fiction writing as a metaphor for doing research from a narrative approach. I will only give a brief summary of the research methodology used by Müller et al. The writing metaphor emphasises the wholeness of the research process.

Müller et al (2001:79ff) propose that the story be developed by using the "ABDCE formula" as methodological point of departure. This formula can be outlined as follows.

\section{- Action}

These are stories of actions (doing things) that are told. The stories include the problem, but primarily deal with the "now" of the stories. In this process the researcher takes the point of "not knowing" (Müller et al 2001:79-81).

\section{- Background}

Background refers to the preceding events to the story. The people involved in the story have a specific religious and cultural background (Müller et al 2001:82-83). The "now" of the story is placed against the current socio-political and economical background.

\section{- $\quad$ Development}

The "plot" or story-line of the drama develops over the course of time. The development takes place in interaction with the "co-researchers". They form part of the development of the story (Müller et al 2001:8486).

\section{- $\quad$ Climax}

Understanding should not come too soon, but should grow in time. The climax cannot be simulated, but should be waited for patiently (Müller et al 2001:89-90).

\section{- $\quad$ Ending}

The ending of the story is not closed but open, the story continues. The end is probably the introduction to a subsequent story (Müller et al 2001:89-90).

This is no linear process, but rather reflects an emergent design which is focused, but nevertheless flexible, iterative and continuous and therefore gives this research the character of an evolving spiral. 


\section{THE DRAMA AS METAPHOR TO DOCUMENT THE RESEARCH EXPERIENCE}

I experienced this research experience in a specific setting in a specific township within my beloved country, South Africa. I wanted the reader to feel and understand something of the passion and love with which I lived and documented these narratives with my co-researchers.

Drama, as a genre, provided me with the metaphor I was looking for. It is a genre which depicts intrigue and plot development in a dramatic way. Through drama I could colour my co-researchers and give names and personalities to the discourses. The narratives and discourses could interact with each other and the plot could develop.

\subsection{The stage}

\subsubsection{The backdrop: Atteridgeville}

The drama is set in Atteridgeville, one of the many townships in South Africa developed by the apartheid government for black people who migrated to the cities in search of work. (Atteridgeville is situated to the west of Pretoria, the capital city of South Africa.)

Neat houses, some big and others small, form the backdrop of this play. Some of the houses are painted in bright colours, pink, yellow and green. Others are plastered in grey and many have huge, decorative gates and front doors.

Street vendors sell vegetables, fruit, chickens, sunglasses and cell phone chargers from stalls on the sidewalks and on street corners. Hordes of children in uniform are making their way home from school, talking, laughing and singing. Colourful women and men from all ages seem to fill the scene, talking in the tarred streets, laughing on the sidewalks and sitting on their "stoeps" in front of tiny green lawns. Taxis hoot their way through crowds, stopping unexpectedly for passengers.

A big red cross on a tower guards the houses and school from a hill on the eastern side of the township. A graveyard kneels in front of the horizon on the western side of the backdrop. The hills on the horizon are covered with tiny dots which when you squint, can be discerned as thousands of shacks.

In front of the backdrop, to the left, backstage, only a few metres from the church, is a white matchbox house with a wired fence and a dilapidated gate. A white vehicle is parked next to the house under a shade net. A man is washing the car. A young woman clings to the man. 


\subsubsection{The décor: Three adjacent rooms at the back of a matchbox house}

Front stage, to the middle, is a black building with a stoep. Two toddlers, a boy and a girl, aged three and two, are playing on the red stoep in the sun. To the right is a concrete basin and an outside toilet in a zink hut. The front door of the black building leads you into a room with a picture of a smiling man in uniform against the opposite wall. If you are familiar with the Zionist Christian Church (ZCC), you will be able to identify the man in the picture as Barnabas Lekganyane, the founder of the ZCC. Two single beds are joined together with a side table and a mirror. The beds take up all the space in the room except for the drawers in one corner. Both beds are neatly covered in bright green and blue check duvet covers and cushions. The room has no windows and the cement floor is bare.

To the left of this room, is another room. The lighting in this room is dimmed, creating the impression of a cold room. The second room can only be entered via a door from the first room. A picture of a brass band of the ZCC hangs above the headboard of the bare double bed. Two dresses, one yellow and green, the other blue and white, both covered in plastic bags, frame the bed on both sides. Next to the bed is a toddler's plastic chair. On top of the chair is a small enamel bucket with two mangos. A wardrobe dating from the sixties decorates the corner next to the window. Under the window two or three white garden chairs are stacked. On the stack of chairs some medicine bottles and a few small plastic bags with pills can be seen. Against the opposite wall hangs another picture of Barnabas Lekganyane. In the opposite corner, is a laundry basket. Diapers are stacked on top of the basket. There are no carpets on the cement floor.

To the left of the stoep, is another door. This door is slightly ajar. A twoplate stove on a table and a fridge can be seen from the outside.

\subsection{The actors}

It is important to note that the actors all portray themselves in this real life drama. Five of the eight main actors in this drama are women, Dina, Nolutando, MamaDina, Mpeki and myself. Dina, Noluthando, MamaDina and Mpeki are all black women and residents of Atteridgeville. Dina and Noluthando are both daughters of MamaDina. Mpeki is my research assistant. I am a white woman who lives in the eastern suburbs of Pretoria.

The three remaining main actors are Aids, Care and Injustice. The workings of Aids and Care are not too difficult to see, even to the untrained eye of a reader not exposed to their interaction. Injustice however, lurks in the 
dark. Neither myself, as character and researcher, nor the reader would have been able to identify Injustice and its devious workings in the dark, if it were't for its surprising manifestation in the last scene. Through reflection on the lived narratives, you could trace back its destructive trail.

The supporting actors in the drama are Stigma \& Discrimination, Patriarchy, Poverty, Religion and Theology and Practical Theology.

\subsection{The script: Basadi ba tswara}

\subsubsection{Act 1: Aids and the terrible twins}

Aids approaches Dina holistically to gain power over her. It uses its strengths as a master of the physical destruction of her body. Aids breaks down Dina's immune system completely and subsequently creates the opportunity for numerous infections to take control of her body. The sores, the skeletal appearance of her body, the hair loss, the weakness, the pain on her face, the constant itching and the loss of bodily functions are all visible signs of the work of these infections.

Slowly but surely, Aids also takes control of Dina's mind. At night, Aids keeps Dina awake with the constant itching caused by the infections. Physically exhausted, it then uses the dark to scare her. It calls on its twins, Stigma and Discrimination, to contaminate the mind of Dina's uncle's girlfriend, the woman that clings to the man (the uncle) in the drama. She is petrified of Aids and a willing instrument for the tricks of the twins. Knowing about the fear of the dark that Aids has created in Dina's mind, the girlfriend switches off the main switch in the matchbox house, causing the backrooms to fall into total darkness. Petrified and trying to get away from the fear, Dina rolls around and falls off the bed. As soon as her screams of pain fill the air, Stigma and Discrimination tickle the girlfriend until she screams with laughter. During the day, she exclaims to passers-by in the street in front of the matchbox house: "Aids lives here, Aids lives here." It is then that anger and frustration jump on the power wagon with Aids and the terrible twins, Stigma and Discrimination, aiming to totally disempower Dina and to leave her without hope. $^{3}$

Stigma and Discrimination also stand in the way of caring from the community. When people hear about Dina's illness "they visited because they wanted to see for themselves but after seeing, they stopped coming", says Noluthando.

\footnotetext{
${ }^{3}$ Pseudonyms are used: the author documented her lived experience over a period of 6 months
} 


\subsubsection{Act 2: The caregivers}

But, by their presence, the women and other visitors to the backyard of the matchbox house challenge the power of Aids. Noluthando, Dina's sister, gets out of bed when she hears the screaming of Dina at night and lifts Dina back onto the bed, calming her down. Early in the morning, shortly after breakfast, Mpeki and Sunette visit her, attentively listening to her storied experiences. A little later in the morning, Dina's mother, MamaDina, joyfully sings her way into the room and soothes away her fear with the magic of touch. She washes Dina, dresses her, puts ointment on her sores, combs her hair and lifts her onto one of the plastic chairs where she can sit upright. She listens to Dina's stories of pain and frustration. Then she puts a fresh blanket on the double bed, sweeps away the dust, opens the windows and sprays air freshener in the four corners of the room. Mid-afternoon, sister Nora pays Dina a visit. Sister Nora is the coordinator of a home-based care program. She asks about Dina's health and gives her medicines from the hospital. Through these caring experiences, Dina claims back some of the power lost to Aids and the terrible twins and a smile of hope lights up her face.

As her sister departs, the priest from the Zion Christian Church enters Dina's room. The women of the Church accompany him. Dina looks up at Religion next to her bed and he winks gently at her. The priest condemns the power that Aids has over Dina and rebukes Aids. The women of the Church sing hymns. It is then that hope is revived within Dina. She believes that one day she will be able to wear one of the uniforms again as she makes her way to church. She smiles at the thought of herself walking again.

\subsubsection{Act 3: A destructive partnership}

Through the presence of the women and the Church in the previous act, Aids feels the power and control over Dina slipping slowly but surely through its fingers. It makes a plan to regain its power. Knowing that Care is easily manipulated, it masterfully befriends Care in its quest for power. Aids persuades the home-based care nurse that good care is only possible through the use of Western medicine. When Dina refuses to drink the Western medicine from the hospital, the nurse furiously storms out of Dina's room, never to return. Dina experiences feelings of rejection and anger. Aids befriends these feelings to break down Dina's resistance to infections. She scratches herself viciously and her coughing becomes more intense.

Aids also manipulates Care into exhausting Noluthando and MamaDina. MamaDina starts dragging her feet during her visits to her daughter and her merry songs dry up. She cries quietly where Dina can't see her. Her burden of care is becoming unbearable. She seems incapable of 
really helping Dina as the bedsores and the pain are getting worse every day. Perhaps a hospice will be able to properly take care of Dina. MamaDina feels so tired. The mere thought of her younger children and Dina's daughter at home fills her heart with devastation. Care has become a heavy burden. She fakes a weak smile when Dina looks up at her. Poverty, the dog of Aids, comes licking at the feet of MamaDina. Her husband works in the Limpopo Province and frequently sends money home, but this month the money is late. Dina asks her mother if she has food for the children. As her mother explains the situation, Poverty jumps on the bed and nestles itself against Dina. She struggles to breathe.

Noluthando thinks about her childhood dreams of studying engineering and starts blaming Care for shattering her dreams. She feels old and ugly. She opens a drawer and put her make-up away

Because of the tricks of Stigma and Discrimination she no longer jumps up at night to help her sister when she falls off the bed. She doesn't have the strength to clean the soiled bedding. She wishes her uncle who lives in the matchbox house would help her, but he obeys the rules of Patriarchy, that prohibits a man from doing a woman's work and caring is, after all, a women's job. She draws the curtains in her sister's room and wishes that her sister would die.

\subsubsection{Act 4: Preferred stories of care}

During their latest visit, Mpeki and myself feel the heaviness in the house, resulting from the destructive relationship between Aids and Care. We decide to reclaim some of the power by befriending Care. We draw back the curtains in Dina's room and listen patiently to the storied experiences of care of Dina, MamaDina and Noluthando. We hear the desperation in their voices. Today is the day for Dina and Noluthando to collect the child support grants at the offices.

Stigma and Discrimination make a trip to the grants offices very difficult, embarrassing and shameful. The uncle doesn't allow Aids into his precious car. Noluthando needs to fetch a wheelchair from the municipal offices and then wheel her sister through the community to the offices. Stigma and Discrimination fill the bystanders' hearts with fear and they either openly stare at the passing parade or talk behind their hands.

Mpeki and myself respond to the need experienced by Dina and her sister Noluthando, and we take them to the grant offices with our car. I also buy Dina some of her favourite food: chocolate, yoghurt and fruit juice. Mpeki chases Poverty away by sharing food and some money with the family. Mpeki and myself invite Noluthando to a movie at a big shopping mall. Noluthando 
carefully takes the make-up out of her drawer, she dresses herself up and meets us at the centre. She gets to choose the movie and the three of us have great fun. Noluthando's father phones from the Northern Province, thanking us for taking Noluthando to the movies.

The next day MamaDina suggests that we go to the municipal offices to transfer the ownership of the matchbox house onto the name of Dina as the uncle has no right to occupy the house. He tore up the title deed a long time ago but MamaDina knows that her father left the house to be inherited by his grandchildren, Dina and Noluthando, because they were the ones that took care of him until he died.

Mpeki and myself take a trip with MamaDina to the municipal offices to sort out the matter. I also volunteer to find out whether there isn't any medication that Dina can use for her itching. I also pay a visit to the hospital in the backdrop and get some surgical gloves for MamaDina. From now on MamaDina uses them all the time. The care provided to the two sisters and their mother fills MamaDina with renewed energy. She starts singing again, while touching Dina, washing her and dressing her. Noluthando is once again wearing make-up. I ask Dina how she feels about her mother taking such good care of her. Dina replies "I love my mother too much". MamaDina's eyes fill with tears of pride. She was so happy that caring could be so meaningful to her daughter. She tenderly touches Dina's hair.

Noluthando suggests that it would be better if she could access the child support grant on behalf of her sister. She doesn't mind, because she loves her sister and she cares for her. When she storied her experience of care, she titled her preferred story: "Caring for someone you love." Her father has secured her a part time job at a chain store in Centurion, a suburb not far from Atteridgeville, and she is excited at this new prospect.

MamaDina, Noluthando, Mpeki and myself have befriended Care and we are a formidable team as we reclaim the power taken from us through the relationship between Aids and Care. MamaDina acknowledges that women are very strong and that caring makes women strong.

Dina starts asking questions about Mpeki's life and my own and gives us some sound advice. There was one week we couldn't visit the family and at the next visit, Dina tells us how she missed us. Dina's father also came to visit her. She adores her father. She adores him because he buys medicines for her from the ZCC shop. Religion is her hero and the medicines make her feel much better. She believes that the medicines will give her the strength to one day walk again.

Dina surprises all the women with her preferred story. She no longer pays any attention to Stigma and Discrimination. When the uncle's girlfriend 
shouts things to people in the street, she yells at the girlfriend to stop her shouting. Stigma and Discrimination are not worthy of her attention and she reports that without attention the terrible twins becomes useless and their tricks cease.

For a very long time, Dina didn't want to go to the hospice although her mother and father thought it to be a good idea. But today Dina agrees. Mpeki and myself promise to visit her in the hospice. Noluthando greets Dina with tears when she leaves the backroom in the yard of the matchbox house for the hospice. Three days after her admission at the hospice, Dina passes away.

\subsubsection{Act 5: The funeral}

The women are devastated. MamaDina doesn't talk, she just cries and cries. Mpeki and myself struggle to understand what had happened since there were no visible signs of deterioration in Dina's health during the last few weeks. Dina was looking so well with all the care she received from the women, the priest and her father.

Dina's father comes home from the Limpopo Province. He blames the hospice. They promised him that they would give Dina the spiritual medicines from the Church, but when he went to fetch her things after her death, he found the unopened bottles on her side table. To make things even worse, the report from the doctors says that she died of AIDS. He feels that they have no right to document her death in that way. I ask if I could contribute towards the costs of the funeral. He politely requests me to assist with the rental of a toilet, to which I agree.

Many strange faces visit the matchbox house during the week of mourning. A tent is pitched in front of the house and three hundred chairs are hired. Noluthando serves cookies she has baked with the help of strangers, using margarine, sugar and flower. She still wears her make-up.

During the week of mourning and on the day of the funeral, amongst the crowd of strange faces, a few familiar faces are also present: Religion, Stigma and Discrimination and Poverty. Religion consoles MamaDina through songs and prayers. Stigma and Discrimination visit to see if Dina really died of "the illness". As the week of mourning is drawing to an end, Poverty finds a hot spot in the sun, patiently waiting for the day of the funeral. He knows there will be plenty to eat.

The family asks me to say something at the funeral after the sermon conducted by the Priest, because I am a friend of the family. I explain to the sea of strange faces that durng the time that I knew the family, I came to understand the real meaning of caring. I talked about the care provided to 
Dina by Noluthando, her mother, her father and the Church. Afterwards, Noluthando is crying. She says it was the first time ever that someone recognised her and thanked her for taking care of her sister.

\subsubsection{Act 6: And the winner is ...}

After the funeral, Aids's dog, Poverty, has moved in with MamaDina.

MamaDina is now taking care of six children in her shack in Jeffsville: seven year old Naledi and five year old Ntswaki, both Dina's children, fourteen year old Lerato, eleven year old Neo and nine year old Maserami, the three of them being MamaDina's own children and two year old Manakedi, Noluthando's child (Noluthando is now working more frequent shifts at the chain store).

Most of the money that her husband earns, is being used to pay off the loan for the funeral. Although the ZCC Church has a funeral scheme, MamaDina never enrolled in it. There is no money for food or taxi fees for the children to go to school. But MamaDina lives her preferred story: she still believes a woman is very strong, so strong that she can even hold on to a sharp knife at the blade to protect her children. She will protect her children like a chicken. Religion also makes her strong as it did her daughter and she prays to God for strength.

The social worker of Heartbeat says that she will help MamaDina access foster care grants for Dina's children. This will bring some more money into the household and will help keep Poverty at bay. Poverty is becoming more arrogant every day.

MamaDina's husband phones me to ask about the grant, but I say that the Department of Social Development has to grant permission at the Children's Court for the organisation to do foster care placements. However, the organisation is currently stuck and awaiting an answer from the Department of Social Development. They have made numerous phone calls and are still awaiting for an answer.

King Patriarchy nods his head in approval. The ancestors of this family had stuck to his rules. MamaDina never finished school because it was not expected from girls to study. Gender stereotyping and culture determined that women should bare children and care for them in the private space of her house, while the men would work in the public domain, providing care by earning an income. Women can earn some income doing things from home, but they should stay home and never earn more than the men. That is not allowed.

The curtain drops while MamaDina is preparing the last few spoons of pap left for the seven hungry children on the two-plate stove in her shack. The youngest one is crying. Two of the kids are fighting over a tomato and the 
eldest child sits in a corner staring at nothing. Then a two-metre tall figure with bulging muscles emerges from the side curtains. He grins maliciously as he grabs MamaDina and pulls her by the hair through the shocked crowd. Her body is chained and she doesn't even make the slightest of sounds.

The rhythmic sound of drums turns the crowd's attention back to the stage. In the spotlight in the front of the stage are two figures. They are embracing each other, both wearing black coats and black masks: Aids and Care. Care holds the tongue of MamaDina in his right hand. He bows. Joining him on stage is the dark figure with the malicious grin. "Meet my best friend ever" Aids shouts, "Injustice!"

\section{CARING INTO EXISTENCE}

Baart (2003:10) uses the metaphor "listening into existence", whereby

... the attention is directly focussed on the human being ... in order to listen him/her into existence, as (s)he is, or potentially can be; in the empty spaces around his/her illness someone shows up and the loneliness (distress squared) is broken, the offer of compassionate understanding is made and the other is - whatever his past or future - restored with respect, recognition and dignity.

I experienced how Dina, Noluthando and MamaDina were restored through respect, recognition and dignity. Their self-re-authoring seemed to have occurred not only because of a listening into existence, but also through presence and responsiveness and thus through "empowering care". And while MamaDina was unable to overcome the injustice of the system, through the caring of Mpeki and myself, she was empowered to re-author a new preferred story of strength. In this sense, I experienced a caring into existence, not only in the instance of the co-researchers, but also with Mpeki and myself.

I would like to explore Baart's metaphor of "listening ... into existence" (Baart 2003:10) in conjunction with the social construction of care, looking at the correlations between "empowering care," as I have outlined it, and "caring into existence." Through empowering care, I experienced works of creation of other, preferred selves. Drama was the most suitable metaphor for this process since it embodies the fundamental elements of empowering care: listening, presence and responsiveness. Drama was able to highlight the process of re-authoring for the co-researchers - from presence, listening, and responsiveness through to the re-experiencing of their stories of care and the actions which followed - and to allow the audience/reader to view this process as it unfolded. Drama could thus most accurately depict the development of the research process and thus the practice of empowering care itself. The 
development of the research project (as an experience in itself) "cared" the preferred selves of Noluthando and MamaDina, Mpeki and myself into existence, into a climax where things were different than before.

The preferred self of Dina was "cared into existence," primarily by her mother, MamaDina, who listened attentively and patiently to Dina's stories, who was present through her caring relationship with Dina and who responded to Dina's needs. It follows that if the research process in this project constituted empowering care and if empowering care was performed by both MamaDina and myself (among others) during this research, then, to a certain extent, neither "research" nor "caring" is something done by "experts" only. Non-experts are able to perform activities with the same empowering implications.

As was demonstrated by my research, it is also possible that experts, and non-experts alike can provide "bad" care when there is an absence of listening, presence and responsiveness. The nurse was an expert in the field of caring, but Dina experienced the care she provided as bad care, since she was neither receptive in her listening nor responsive to the needs expressed by Dina. Nor can we conclude that care by and for related persons is necessarily bad care since Dina experienced the care of her mother, father, and eventually from her sister as good care. It should also be noted, however, that care by and for unrelated persons is not necessarily bad or worse than private care (by family members) since there is a reason to believe that professional carers, by virtue of their training as well as their much more wideranging and varied experience, make better carers than lay carers.

Care as a highly gendered activity performed mainly by women was deconstructed in the project. The assumption that care is a strictly a female role, was also challenged by Dina's experience of good care from her Priest, a male, and her experience of bad care from her sister. Again, the good care was "empowering care." We could conclude by saying that in this research experience, good care seems to have little to do with gender stereotypes.

The "l" in this research experience was also cared into another existence, a new preferred self. While storying and living this research experience, I lived new preferred stories of care with my son. I preferred to live a story of empowering care, a caring into existence and marvelled at my son's re-authored self. Deconstructing the highly gendered construct of care as a female activity also empowered me to interpret my own "lack of care" as constituted in my culture.

This project was most significantly about allowing the voices of the women infected and/or affected by HIVIAIDS to have an audience. And although change was not the purpose of this project, it might just be that these 
stories inspire structural change, a prerequisite for MamaDina to experience and to live a story of good care.

\section{Works consulted}

Anderson, $\mathrm{H}$ \& H Goolishian 1992. The client is the expert: A not-knowing approach to therapy, in S McNamee and K J Gergen (eds), Therapy as social construction, 25-39. London: Sage.

Baart, A 2003. The fragile power of listening. Unpublished article. Mission Maryknoll. New York: Orbis Books.

Botha, A 1998. Pastoral therapy and extra marital affairs: A narrative approach. DTh thesis, University of South Africa, Pretoria:

Brittan, A 1989. Masculinity and power. Oxford: Blackwell.

Brueggemann, W 1987. The prophetic imagination. Philadelphia, PA: Fortress.

Burr, V 1995. An introduction to social constructionism. London: Routledge.

Dill, J 1996. 'n Basisteorie vir pastorale terapie in die lig van postmoderne epistemologie. PhD-proefskrif, Universiteit van die Oranje Vrystaat, Bloemfontein.

Dixon, G 1999. Narrative, journaling, therapy and abuse: Co-searching women's lives. Unpublished PhD Dissertation, University of Otago: New Zealand.

Dorrington, Robert 1999a. ASSA600 [programme], Actuarial Society of South Africa.

Dudley-Marling, C 1996. On becoming, in Heshusius, L \& Ballard, K (eds), From positivism to interpretivism and beyond: Tales of transformation in educational and social research (The mind-body connection). New York: Teachers College Press.

Freedman, J \& G Combs 1996. Narrative therapy. New York: Norton.

Gerkin, C V 1997. An introduction to pastoral care. Nashville,TN: Abingdon.

Griffen, D. R 1989. God and religion in the postmodern world. Albany, NY: State University of New York Press.

Hare-Mustin, R. T 1997. Discourse in the mirrored room: A postmodern analysis of therapy, in M M Gergen \& S N Davis (eds), Toward a new psychology of gender: A Reader, 553-572. New York: Routledge.

Herholdt, M D 1998a. Postmodern hermeneutics, in S Maimela \& A König (eds), Initiation into theology, 451-470. Pretoria: J L van Schaik.

Jobson, M D 2000. The intersections of gender, HIVIAIDS and human rights. Centre for Gender Studies, University of Pretoria, Pretoria.

Kotzé, E 1994. The social construction of a family therapy training programme. DLitt et Phil Thesis, Rand Afrikaans University.

Kotzé, E \& D J Kotzé 1997. Social construction as postmodern discourse: An epistemology for conversational therapeutic practise. Acta Theologica 17(1), 27-50.

Landman, C 1998. African women's theology, in S S Mailmela \& A König (eds), Initiation into theology, 137-140. Pretoria: J L van Schaik.

Morgan, A 2000. What is narrative therapy? An easy-to-read introduction. Adelaide: Dulwich Centre Publications.

Müller, J C, Van Deventer, W V \& Human, L 2001. Fiction writing as metaphor for research: A narrative approach. Practical Theology in South Africa 26(2). Pretoria. 
Olesen, V 1994. Feminism and models of qualitative research, in N K Denzin \& Y S Licoln (eds), Handbook of qualitative research, 158-174. Thousand Oaks: Sage.

White, M 1995b. Re-authoring lives: Interviews and essays. Adelaide: Dulwich Centre.

Whiteside, A \& Sunter, C 2000. AIDS The challenge for South Africa. Tafelberg: Human \& Rousseau. 